\title{
EXPERIMENTAL HYPERTONICITY: ALTERATIONS IN THE DISTRIBUTION OF BODY WATER, AND THE CAUSE OF DEATH ${ }^{1}$
}

\author{
By ALEXANDER W. WINKLER, J. RUSSELL ELKINTON,2 JAMES HOPPER, JR., \\ AND HEBBEL E. HOFF
}

(From the Department of Internal Medicine and the Laboratory of Physiology, Yale University School of Medicine, New Haven)

(Received for publication July 2, 1943)

In dogs deprived of food and water, water is lost out of proportion to the loss of salt. Concentrations of sodium and of chloride in serum therefore rise progressively for many days, until, just before death, concentrations as high as 186 m.Eq. of sodium and $133 \mathrm{~m} . \mathrm{Eq}$. of chloride per liter of serum have been found (1). It was not, however, clear whether death was due to the hypertonicity of the body fluids or to the concomitant dehydration. In certain of the present experiments, a comparable degree of hypertonicity has been produced acutely, without reducing the total body water. In others, hypertonic solutions were administered to animals already dehydrated. The reactions of the animals have been compared with those of the animals in which hypertonicity resulted from water loss alone.

\section{MATERIALS AND METHODS}

Twelve dogs in all were used. Chemical data relating to the fluid and salt exchanges of 8 of them are presented in the preceding paper (2). Two received 5 per cent saline intravenously, the rest intraperitoneally. Four of the animals had their ureters ligated just before the experiment. Dial anesthesia was used in 9 of the acute experiments, morphine in 1 acute experiment, and no anesthetic in the 2 chronic experiments.

After the anesthetic had taken effect, the animal was weighed, and a preliminary blood sample and electrocardiogram were obtained. Sodium chloride in 5 per cent solution was then injected intravenously or intraperitoneally. In some experiments, peritoneal fluid was removed after 30 or $\mathbf{4 0}$ minutes, in amounts approximating or somewhat exceeding the volume of saline injected. This fluid always contained salt in a concentration much lower than 5 per cent. Serial electrocardiograms were obtained from time to time. In some instances, further

1 Aided by grants from the Fluid Research Fund of Yale University, the Ella Sachs Plotz Fund, and the John and Mary R. Markle Foundation.

2 National Research Council Fellow in the Medical Sciences, $1940-42$.

3 American College of Physicians Fellow, 1942-43. injections of saline were given. As far as possible, the animals were kept under continuous observation until death, while respiration, pulse, and other clinical data were noted periodically. Every attempt was made to be present at the exact moment of death and to obtain a terminal blood specimen and body weight. Sometimes the blood was obtained a little while before death.

Methods of chemical analysis, of measurement of plasma volume, and of estimating changes in intracellular, extracellular, and total water have been described in detail elsewhere $(1,4,5)$. The symbols and formulae used have been summarized in the preceding paper (2), and will not be repeated here.

\section{RESULTS}

(a) Changes in concentration of electrolytes and in distribution of body water

The results of 4 typical experiments, 2 acute and 2 chronic, are presented in Tables I and II. In the 2 acute experiments (Experiments 27 and 28), 5 per cent sodium chloride was injected intraperitoneally with subsequent withdrawal of a comparable volume of peritoneal fluid, containing much less salt. The procedure resulted in a considerable addition of sodium chloride to the body without affecting much the total water content. The animals were then followed until death occurred, after 8 and 11 hours, respectively. In the 2 chronic experiments (Experiments 25B and 29), the animals received neither food nor water during the 8 days prior to the first intraperitoneal injection of 5 per cent saline. This solution was then injected in $50 \mathrm{cc}$. amounts, intraperitoneally, 2 or 3 times a day until death occurred, on the twelfth and on the fourteenth days, respectively. No peritoneal fluid was withdrawn. Dial anesthesia was used in the acute experiments but not in the chronic ones.

In the 2 acute experiments, serum concentration of sodium had increased by 40 or 50 per cent just prior to death (Table II). Chloride 
TABLE I

Exchanges of water, electrolytes, and nitrogen

\begin{tabular}{|c|c|c|c|c|c|c|c|c|c|c|}
\hline \multirow{2}{*}{$\begin{array}{c}\text { Experi- } \\
\text { ment }\end{array}$} & \multirow{2}{*}{$\begin{array}{l}\text { Time from } \\
\text { start of } \\
\text { experiment }\end{array}$} & \multirow{2}{*}{$\underset{\text { weight }}{\text { Body }}$} & \multicolumn{3}{|c|}{ Net intraperitoneal intake* } & \multicolumn{3}{|c|}{ Urinary output } & \multicolumn{2}{|c|}{ Balance } \\
\hline & & & $\mathrm{H}_{2} \mathrm{O}$ & $\mathrm{Na}$ & $\mathrm{Cl}$ & $\mathrm{H}_{2} \mathrm{O}$ & $\mathrm{Na}$ & $\mathrm{Cl}$ & $\mathbf{N}$ & $\mathbf{K}$ \\
\hline 27 & $\begin{array}{c}\text { days } \\
0 \\
0.3\end{array}$ & $\begin{array}{l}\mathrm{kgm} . \\
7.85 \\
7.83\end{array}$ & $\begin{array}{l}c c . \\
125\end{array}$ & $\begin{array}{l}\text { m. eq. } \\
364.2\end{array}$ & $\begin{array}{l}\text { m. eq. } \\
369.3\end{array}$ & $\begin{array}{l}c c . \\
0\end{array}$ & $\begin{array}{c}\text { m. eq. } \\
0\end{array}$ & $\begin{array}{c}\text { m. eq. } \\
0\end{array}$ & $\begin{array}{l}\text { grams } \\
-0.10\end{array}$ & $\begin{array}{l}\text { m. eq. } \\
-2.1\end{array}$ \\
\hline 28 & $\begin{array}{l}0 \\
0.5\end{array}$ & $\begin{array}{l}6.64 \\
6.24\end{array}$ & -51 & 289.5 & 309.3 & 27 & 5.0 & 6.9 & -0.64 & -4.9 \\
\hline $25 B$ & $\begin{array}{r}0 \\
8 \\
10 \\
12\end{array}$ & $\begin{array}{l}8.52 \\
7.12 \\
6.82 \\
6.62\end{array}$ & $\begin{array}{l}-8 \\
111 \\
150\end{array}$ & $\begin{array}{l}-1.1 \\
122.3 \\
162.7\end{array}$ & $\begin{array}{l}-0.6 \\
124.0 \\
165.0\end{array}$ & $\begin{array}{l}350 \\
120 \\
115\end{array}$ & $\begin{array}{l}74.2 \\
85.4 \\
80.7\end{array}$ & $\begin{array}{l}41.0 \\
76.0 \\
75.6\end{array}$ & $\begin{array}{l}-12.20 \\
=2.67 \\
-3.52\end{array}$ & $\begin{array}{l}-52.0 \\
=9.6 \\
-8.6\end{array}$ \\
\hline 29 & $\begin{array}{r}0 \\
8 \\
10 \\
12 \\
14\end{array}$ & $\begin{array}{l}7.86 \\
6.59 \\
6.33 \\
6.04 \\
5.71\end{array}$ & $\begin{array}{l}-8 \\
260 \\
103 \\
117\end{array}$ & $\begin{array}{l}-1.1 \\
249.9 \\
119.9\end{array}$ & $\begin{array}{l}-0.6 \\
251.3 \\
121.6 \\
187.6\end{array}$ & $\begin{array}{l}230 \\
325 \\
235 \\
212\end{array}$ & $\begin{array}{r}48.0 \\
157.8 \\
126.5\end{array}$ & $\begin{array}{r}23.8 \\
150.2 \\
134.2 \\
108.5\end{array}$ & $\begin{array}{r}-14.28 \\
=\quad 5.54 \\
=\quad 5.98 \\
-\quad 3.70\end{array}$ & $\begin{array}{l}-46.7 \\
-23.7 \\
-17.3 \\
-4.9\end{array}$ \\
\hline
\end{tabular}

* Corrected for serum taken for analysis and saline solution of dye, T-1824, injected intravenously. In Dogs 27 and 28 , peritoneal fluid was also withdrawn.

† Weights corrected for solids lost.

In both tables, time from start of experiment indicates end of period, at which time serum analyses were made and balances determined. Quantities are expressed per individual period rather than cumulatively. In designation of experiment, number refers to the individual dog; where a dog was used more than once, letter refers to successive experiments.

concentrations had risen to an even greater extent. In the 2 chronic experiments, the concentrations of sodium and of chloride, which had changed only slightly in the preliminary 8-day period of simple water deprivation, rose after repeated intraperitoneal injections of hypertonic saline to levels comparable to those found in the acute experiments. In the chronic experiments, unlike the acute ones, a large share of the injected sodium chloride was eliminated daily in the urine, so that the net positive balance of salt increased only gradually.

Extracellular fluid volume, whether calculated from the sodium or from the chloride balances, increased following hypertonic saline injections in all 4 experiments. In the 2 acute experiments, the increases were 70 and 40 per cent, respectively. In the 2 chronic experiments, there had been a decrease of the extracellular fluid volume during the 8 days of preliminary dehydration, and repeated injections of hypertonic saline were followed by a partial restoration of the extracellular fluid volume to normal.

Intracellular fluid volume declined in all $4 \mathrm{ex}-$ periments (Table II). In the 2 acute experiments, the 2 independent methods which were used in the estimation of intracellular fluid change were in approximate agreement, the determination by means of the potassium balance giving somewhat lower results. Since, in both these acute experiments, there were only trivial changes in the total body water (Table II), the great expansion of the extracellular fluid was almost wholly at the expense of an equivalent reduction of the intracellular fluid. In the 2 chronic experiments, total water, intracellular fluid, and extracellular fluid had all decreased to approximately the same extent during the 8 days of preliminary simple dehydration. The subsequent injection of hypertonic saline resulted in still further depletion of the total water. Since extracellular fluid volume here too increased, there was a decrease of intracellular fluid exceeding that of the total water.

Measurements of plasma volume are presented in Table II. In the 2 acute experiments, only serum protein determinations are available. Concentration of protein dropped sharply; assuming no loss of circulating protein, this would mean that the plasma volume had expanded. In the 2 chronic experiments, total plasma volume was determined in two ways, from the distribution of Evans blue dye and independently from carbon monoxide distribution and relative cell volume. There was a moderate decrease of plasma volume during the 
8-day period of dehydration. With the administration of intraperitoneal salt solution, plasma volume reexpanded. These changes closely parallel those of the extracellular fluid, and are opposed in direction to those of the intracellular fluid.

Hypertonic saline was given in a similar fashion to 8 other animals, in addition to the 4 which have just been described, with fatal results in 6 . In Figure 1, the percentage changes of total water, of extracellular fluid, and of intracellular fluid have been compared with those in the 4 experiments which have just been described. The changes in plasma volume in Experiments 25B and 29 have been included for comparison. Extracellular fluid consistently increases, intracellular consistently decreases, and total water is little affected. Plasma volume changes parallel those in extracellular fluid. The extent of the distortion in distribution of body water is roughly proportional to the amount of extra salt in the body (abscissae).

\section{(b) Toxic effects on circulation and respiration, and the mode of death}

The peripheral pulse was slow and vigorous until the very end in both chronic and acute ex- periments (Experiments 27, 28, 25B, 29). In 3 of them, death occurred while the animals were actually under continuous observation. In all 3 , death resulted from cessation of respiration 1 to 11 hours after the last injection of hypertonic saline, while the heart was still beating effectively. Shortly before the end, respirations began to be irregular and somewhat periodic. In the chronic unanesthetized dogs, there were muscular tremors, hyperactive reflexes, and some incoordination, but no true convulsions. The high plasma volumes just before death, the failure of the blood nonprotein nitrogen concentration to rise, and the continued excretion of urine in the chronic experiments, all indicate that the circulation was functionally well-maintained until the end.

Serial electrocardiographic studies were made at intervals in these 4 experiments, and in 8 others as well. Some observations of pulse and of the manner of death were also made in these other 8 experiments. $T$ wave changes, variable in extent and character, were usually encountered soon after injection. Fluctuation in the $T$ wave pattern sometimes occurred during the course of the ex-

TABLE II

Analytical data, determinations of plasma volume, and calculation of changes in body fluid phases

\begin{tabular}{|c|c|c|c|c|c|c|c|c|c|c|c|c|c|c|c|}
\hline \multirow{2}{*}{$\begin{array}{c}\text { Experi- } \\
\text { ment }\end{array}$} & \multirow{2}{*}{$\begin{array}{c}\text { Time } \\
\text { from } \\
\text { start of } \\
\text { experi- } \\
\text { ment }\end{array}$} & \multicolumn{5}{|c|}{ Serum concentration } & \multicolumn{2}{|c|}{ Blood } & \multicolumn{2}{|c|}{ Plasma volume } & \multirow{2}{*}{$\Delta \mathrm{W}_{\mathrm{I}}^{*}$} & \multirow{2}{*}{$\Delta \mathbf{E}_{\mathrm{Cl}^{\dagger}}^{\dagger}$} & \multirow{2}{*}{$\Delta \mathrm{E}_{\mathrm{Na}} \ddagger$} & \multirow{2}{*}{$\Delta \mathrm{I}_{\mathrm{I}} \mathrm{z}$} & \multirow{2}{*}{$\Delta \mathrm{I}_{\mathrm{II}} \mathrm{ll}$} \\
\hline & & $\mathrm{Na}$ & $\mathrm{Cl}$ & $\mathbf{K}$ & $\mathrm{H}_{2} \mathrm{O}$ & $\begin{array}{l}\text { Total } \\
\text { protein }\end{array}$ & $\begin{array}{l}\text { Hema- } \\
\text { tocrit }\end{array}$ & $\begin{array}{l}\text { Conc. } \\
\text { NPN }\end{array}$ & $\begin{array}{c}\mathrm{CO} \\
\text { method }\end{array}$ & $\begin{array}{c}\text { Dye } \\
\text { method }\end{array} \mid$ & & & & & \\
\hline 27 & $\begin{array}{l}\text { days } \\
0 \\
0.3\end{array}$ & 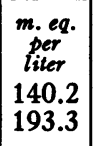 & \begin{tabular}{|c|} 
m. eq. \\
per \\
liter \\
104.3 \\
170.5
\end{tabular} & 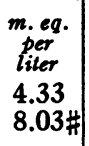 & $\begin{array}{c}\text { grams } \\
\text { per } \\
\text { liter } \\
936 \\
948\end{array}$ & $\begin{array}{c}\text { grams } \\
\text { per } \\
\text { cent } \\
6.51 \\
4.61\end{array}$ & $\begin{array}{l}\text { per } \\
\text { cent } \\
\text { cells }\end{array}$ & 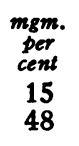 & $c c$. & cc. & $\begin{array}{l}\text { liters } \\
-0.02\end{array}$ & $\begin{array}{l}\text { liters } \\
+1.37\end{array}$ & $\begin{array}{l}\text { liters } \\
+1.36\end{array}$ & $\begin{array}{l}\text { liters } \\
-1.35\end{array}$ & $\begin{array}{l}\text { liters } \\
-0.90\end{array}$ \\
\hline 28 & $\begin{array}{l}0 \\
0.5\end{array}$ & $\begin{array}{l}136.0 \\
212.8\end{array}$ & $\begin{array}{l}102.3 \\
185.8\end{array}$ & $\begin{array}{l}4.80 \\
5.32\end{array}$ & $\begin{array}{l}941 \\
949\end{array}$ & $\begin{array}{l}5.92 \\
4.64\end{array}$ & & $\begin{array}{l}30 \\
41\end{array}$ & & & -0.40 & +0.73 & +0.74 & -1.13 & -0.96 \\
\hline 25B & $\begin{array}{r}0 \\
8 \\
10 \\
12\end{array}$ & \begin{tabular}{|l|}
143.4 \\
144.9 \\
155.8 \\
179.6
\end{tabular} & $\begin{array}{l}109.9 \\
117.1 \\
127.8 \\
133.3\end{array}$ & $\begin{array}{l}5.19 \\
4.59 \\
4.59 \\
4.31\end{array}$ & $\begin{array}{l}935 \\
932 \\
942 \\
933\end{array}$ & $\begin{array}{l}5.86 \\
6.83 \\
6.08 \\
5.44\end{array}$ & $\begin{array}{l}41.3 \\
47.4 \\
42.8 \\
31.0\end{array}$ & $\begin{array}{l}25 \\
26 \\
20 \\
19\end{array}$ & $\begin{array}{l}523 \\
368 \\
362\end{array}$ & $\begin{array}{l}548 \\
409 \\
426 \\
454\end{array}$ & $\begin{array}{r}-1.05 \\
-0.22 \\
-0.12\end{array}$ & $\begin{array}{r}-0.45 \\
+0.21 \\
+0.50\end{array}$ & $\begin{array}{r}-0.53 \\
+0.14 \\
+0.19\end{array}$ & $\begin{array}{l}-0.60 \\
-0.43 \\
-0.62\end{array}$ & $\begin{array}{l}-0.37 \\
-0.23 \\
-0.45\end{array}$ \\
\hline 29 & $\begin{array}{r}0 \\
8 \\
10 \\
12 \\
14\end{array}$ & \begin{tabular}{|l|}
148.5 \\
144.0 \\
165.7 \\
173.6 \\
213.4
\end{tabular} & $\begin{array}{l}110.1 \\
117.5 \\
135.9 \\
143.8 \\
193.0\end{array}$ & $\begin{array}{l}4.37 \\
4.61 \\
4.50 \\
3.40 \\
3.00\end{array}$ & $\begin{array}{l}941 \\
936 \\
942 \\
942 \\
945\end{array}$ & $\begin{array}{l}\mathbf{5 . 6 7} \\
\mathbf{5 . 7 5} \\
\mathbf{5 . 4 3} \\
\mathbf{5 . 3 1} \\
\mathbf{4 . 9 8}\end{array}$ & $\begin{array}{l}45.4 \\
46.6 \\
38.7 \\
34.8 \\
25.2\end{array}$ & $\begin{array}{l}23 \\
29 \\
16 \\
29 \\
22\end{array}$ & $\begin{array}{l}484 \\
352 \\
420 \\
398\end{array}$ & $\begin{array}{l}452 \\
374 \\
379 \\
402 \\
402\end{array}$ & $\begin{array}{l}-0.95 \\
-0.18 \\
-0.22 \\
-0.25\end{array}$ & $\begin{array}{r}-0.31 \\
+0.45 \\
-0.20 \\
-0.12\end{array}$ & $\begin{array}{l}-0.28 \\
+0.36 \\
-0.13\end{array}$ & $\begin{array}{l}-0.64 \\
-0.63 \\
-0.02 \\
-0.13\end{array}$ & $\begin{array}{l}-0.28 \\
-0.50 \\
-0.20 \\
-0.48\end{array}$ \\
\hline
\end{tabular}

* $\Delta W_{I}=$ change in total water volume (Equations $1,2(2)$ ).

$\dagger \Delta \mathrm{E}_{\mathrm{Cl}}=$ change in extracellular water volume (Equations 4,5 (2)).

$\ddagger \Delta \mathrm{E}_{\mathrm{Na}}=$ change in extracellular water volume (Equations 4,6 (2)).

$\$ \Delta \mathrm{I}_{\mathrm{I}}=$ change in intracellular water volume (Equation 10 (2)).

$\| \Delta \mathrm{III}=$ change in intracellular water volume (Equation 11 (2)).

\# Blood drawn after respirations had stopped. 

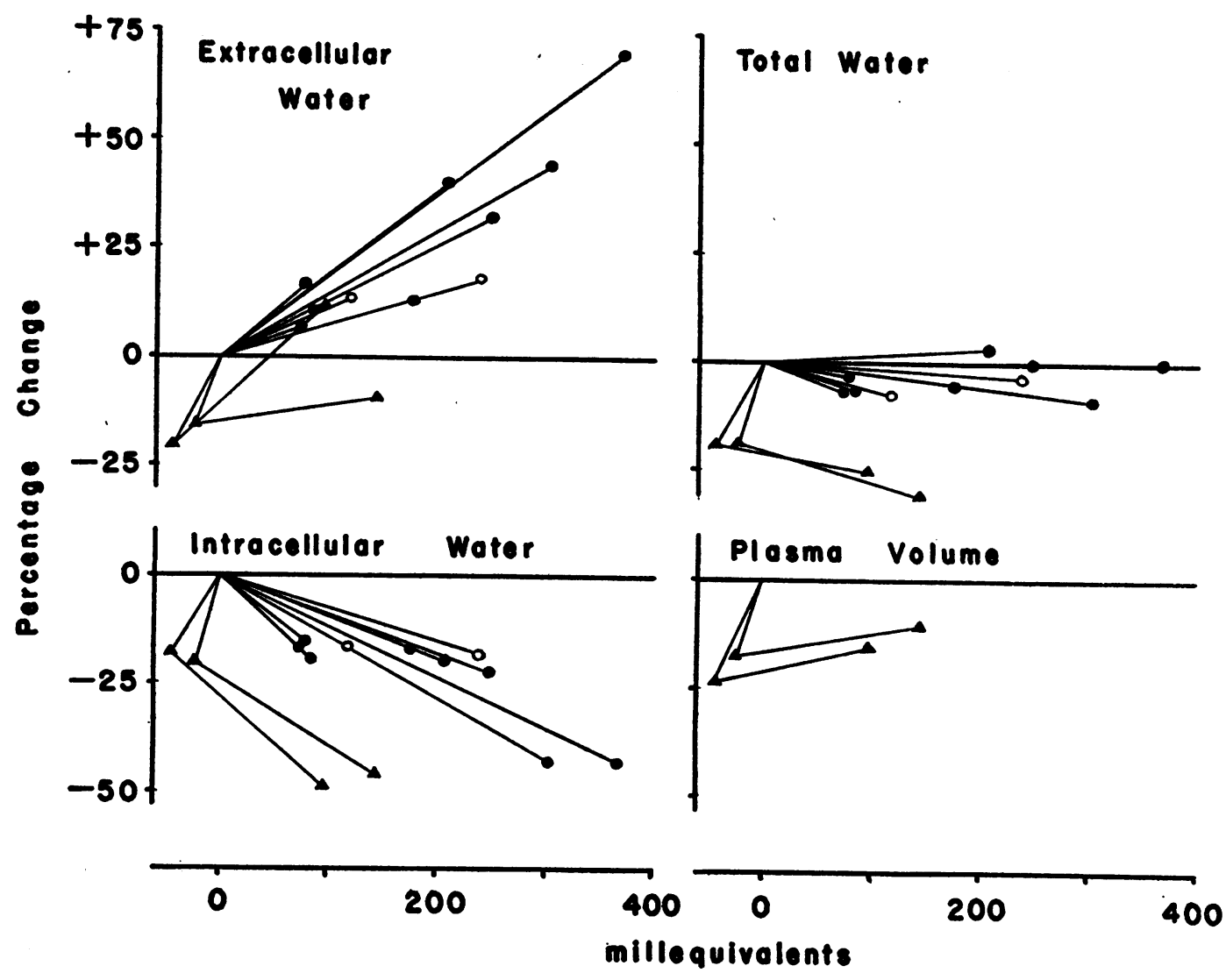

Extra Chloride. in Body.

Fig. 1. Comparison of the Percentage Changes in Extracellular, Intracellular, and Total Water Volumes, and Plasma Volumes, with the Amount of Extra Salt in the Body, in 12 Dogs Made Hypertonic by the Injection of Sodium Chloride

Changes in volumes are plotted along the ordinates, while amounts of extra chloride are plotted along the abscissae. Solid black triangles represent the dogs deprived of water for a period before receiving the salt injections, open circles represent the 2 dogs that survived, and solid black circles represent the rest of the animals.

periments, even when the concentration of base or the distribution of water was not changing. Occasionally, a depression of the ST segment would appear immediately following the introduction of the hypertonic solution, but usually reverted to normal, even when no additional salt was given. Heart block developed terminally in one experiment, but this may well have been the result of an injury by a needle during a cardiac puncture. All in all, the electrocardiogram deviated very little from normal in any of the experiments, and just prior to death the complexes were usually essentially unchanged.

In Figure 2 are charted the concentrations of sodium, of chloride, and of potassium, at or just prior to death, in 10 experiments which resulted fatally. The maximal concentrations observed in the 2 dogs that eventually recovered after receiving large amounts of hypertonic saline are also included. In 2 instances (one associated with heart block, the other when blood was taken after respirations had stopped), there was a moderate increase in the serum potassium, while in the rest, its concentration was normal. Chloride and sodium were regularly markedly elevated, both roughly in proportion to the amount of extra salt in the body. There is no good evidence of any critical concentration, however, since death sometimes occurred at concentrations below those tolerated by the 2 dogs which survived. 


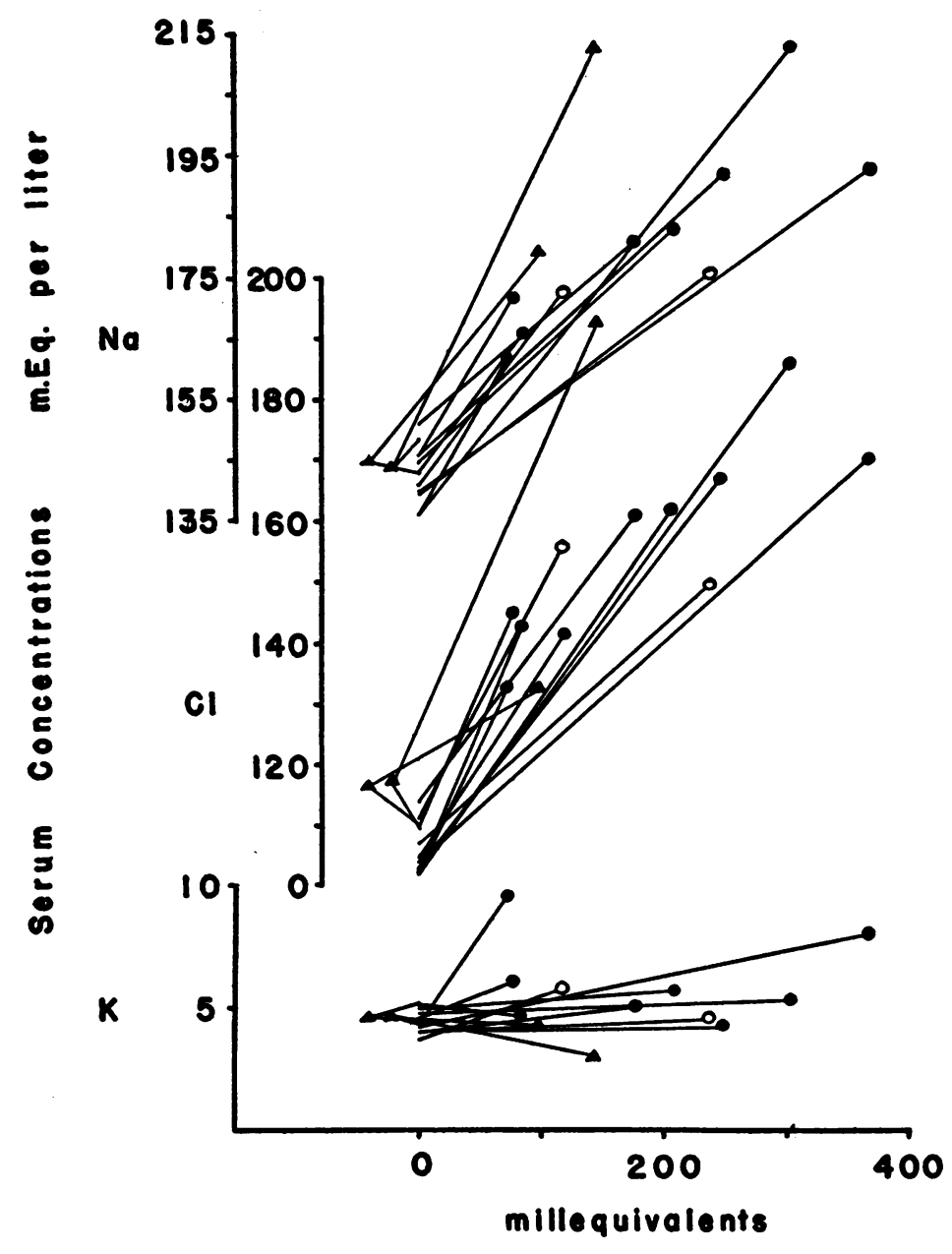

Extra Chloride in Body

Fig. 2. Comparison of the Concentrations in Serum of Na, Cl, and $K$ and the Amount of Extra Salt in the Body, in 12 Dogs Made Hypertonic by the Injection of Sodium Chloride

Concentrations in serum are plotted along the ordinates and amounts of extra chloride along the abscissa. Symbols are as in Figure 1.

\section{DISCUSSION}

Parenteral injection of hypertonic saline in sufficiently large amounts evidently may cause death. Whatever the ill effects produced by such hypertonic solutions, they clearly do not include impairment of the circulation. Death was apparently due to respiratory failure, the circulation remaining adequate until the end. This remarkably satisfactory state of the circulation in animals soon to die was associated with an expanded state of the extracellular fluid. Electrocardiographic changes were minimal, pulse was vigorous, plasma volume was high, and renal activity was well maintained. Clearly, there was no potassium poisoning (Figure 2). Even in animals previously dehydrated for 8 days, the circulation was in nowise depressed by repeated injections of hypertonic saline; indeed, the plasma volume actually increased slightly.

Hypertonicity in our experiments with saline injection was invariably associated with a reduction in intracellular fluid volume. No way could be devised to increase the concentration of extracellular salt without causing a simultaneous os- 
motic shift from the intracellular to the extracellular phase. Injection of potassium salts would have been useless, since Eichelberger (3) has already shown that this procedure fails to expand the intracellular phase. Temporary hypertonicity of the body fluid, with minimal initial distortion of its partition between cells and interstitial fluid, was actually produced by injections of urea in concentrated solution (2). Urea crosses most cell membranes freely. With the amounts used, no deleterious effects developed. This is perhaps some indication that hypertonicity per se may be relatively unimportant. Also, the same amount of saline is required to kill an animal by intravenous injection as by peritoneal injection, yet the transient concentrations of sodium and of chloride during intravenous injection must have greatly exceeded those following intraperitoneal injection. This is another bit of evidence suggesting that the degree of contraction of intracellular fluid may be more important than the actual concentration of circulating electrolytes.

Certainly there must be some lower limit below which intracellular dehydration cannot be tolerated, since the complex metabolism of cells cannot continue in a dessicated state. Equally clearly, on the basis of our experiments (Figure 1) and of those reported by Elkinton and Taffel (1), cells can sometimes function until they have lost 40 to 50 per cent of their water. It is hard, consequently, to assess the degree to which a less severe contraction of intracellular fluid limits the organism. Reductions of intracellular volume of 16 to 20 per cent, found in 5 of the fatal cases, were also found in the 2 chronic dogs before receiving saline, and in the 2 acute dogs which survived. Reductions of this magnitude, therefore, seem hardly sufficient to be wholly responsible for death. Possibly in some cases, there was a synergistic action between the intracellular dehydration and the depression due to the anesthetic. It is also possible that dehydration is best tolerated when produced gradually. General loss of cell fluid may include dehydration of the cells of the central nervous system as well. If this were the case, dehydration of the cells of the respiratory centers might at least contribute to the respiratory arrest from which the animals die. Whether or not cellular dehydration in the brain and elsewhere is responsible for the fatal effect with hy- pertonic injections cannot, however, be decided without further experimentation. The dehydrated animals managed to survive for several days in spite of daily hypertonic saline injections.

Several mechanisms of adjustment were called into play to mitigate the deleterious effects of hypertonic injections. Perhaps the most important of these was the excretion of an abnormally concentrated urine, the chloride concentration at times exceeding 600 m.eq. per liter of urine. Although concentrations of this degree are unusual, the $U / P$ ratio did not much exceed that commonly found in the dog, because of the simultaneous hypertonicity of the plasma. As a result, urine was excreted containing salt in concentration almost, but not quite, equaling that in the injected fluid. Urine volume was high enough so that total water loss proceeded about as fast as in the control animals receiving no injections. This urinary efficiency was only possible with an excellent circulation, which was in turn assured by the maintenance of large extracellular and plasma volumes.

A clinical state comparable to that of our animals might result from the consumption of sea water by man. Vomiting or diarrhea, if present, would of course have deleterious effects other than those studied here. If, however, any or all of the sea water were absorbed, our results are relevant. Assuming that the reactions of man are at least qualitatively similar to those of the dog, the sequence of events following the absorption of sea water may be outlined. At first, there would be an increase in the total water of the body, with a disproportionate increase in the extracellular fluid and a decrease in the intracellular fluid. Since the large extracellular fluid would favor an adequate renal flow, increased urinary excretion of water and salt would be expected. This would approximate in volume the amount of fluid absorbed, so that in the end dehydration would not be mitigated. The concentration of salt in the urine would presumably be less than that observed in our experiments, since the human kidney cannot concentrate urine quite as well as can that of the dog, and would certainly be less than its concentration in the ingested sea water. The final result would be an increase in the extracellular fluid, an equivalent decrease in the intracellular fluid, and an increase in the tonicity of all the 
body fluids. It is not known whether death from respiratory failure has ever occurred in human beings who have carried this process far enough, but it is reasonable to predict its eventual development.

\section{CONCLUSIONS}

(1) Dogs may be killed by the introduction of a sufficient amount of sodium chloride into the body, provided the total body water does not change significantly.

(2) Introduction of sodium chloride, without change in body water, results in an increase in the volume of the extracellular fluid at the expense of a comparable decrease in the volume of the intracellular fluid. Both phases become hypertonic.

(3) The cardiovascular system is apparently unaffected by these developments. Electrocardiograms are little changed, plasma volume and renal function are well maintained.

(4) Death usually results from respiratory failure.
(5) It is suggested that intracellular dehydration, particularly affecting the cells of the respiratory centers, is the main but not the sole cause of death. There is no evidence for the existence of a critical lethal concentration of either sodium or chloride.

\section{BIBLIOGRAPHY}

1. Elkinton, J. R., and Taffel, M., Prolonged water deprivation in the dog. J. Clin. Invest., 1942, 21, 787.

2. Elkinton, J. R., and Winkler, A. W., Transfers of intracellular potassium in experimental dehydration. J. Clin. Invest., 1944, 23, 93.

3. Eichelberger, L., The distribution of body water in skeletal muscle and liver in normal dogs following injections of potassium salts. J. Biol. Chem., 1941, 138, 583.

4. Hopper, J., Jr., and Tabor, H., Adaptation of the palladium method for the determination of carbon monoxide to the calculation of blood volume. To be published.

5. Hopper, J., Jr., and Winkler, A. W., The simultaneous determination of blood volume in man and dog by means of Evans blue dye, T-1824, and by means of carbon monoxide. To be published. 